\title{
Non-thermal Plasma-activated Medium Induces Apoptosis of Aspc1 Cells Through the ROS-dependent Autophagy Pathway
}

\author{
XING ZHEN ${ }^{1 *}$, HU-NAN SUN ${ }^{2 *}$, REN LIU $^{1}$, HACK SUN CHOI ${ }^{3}$ and DONG-SUN LEE ${ }^{1,3,4}$ \\ ${ }^{1}$ Interdisciplinary Graduate Program in Advanced Convergence Technology and Science, \\ Jeju National University, Jeju, Republic of Korea; \\ ${ }^{2}$ Department of Disease Model Animal Research Center, College of Life Science and Technology, \\ Heilongjiang Bayi Agricultural University, Daqing, P.R. China; \\ ${ }^{3}$ Subtropical/Tropical Organism Gene Bank, Jeju National University, Jeju, Republic of Korea; \\ ${ }^{4}$ Practical Translational Research Center, Jeju National University, Jeju, Republic of Korea
}

\begin{abstract}
Background/Aim: Numerous studies on various cancer cell lines have reported that direct exposure to nonthermal plasma treatment using plasma-activated medium (PAM) can be applied as a novel technology for cancer therapy. In this study, we investigated the inhibitory effects of PAM on Aspcl pancreatic cancer cells and the mechanisms responsible for the cell death observed. Materials and Methods: A colony-formation, sphereformation, wound-healing and transwell assays, immunocytochemistry and western blot analysis were used monitor effects of PAM. Results: PAM induced a greater cytotoxic effect in pancreatic cancer cells compared to that induced in NIH3T3 cells and 293 Tells, and significantly inhibited colony and sphere formation, and cell migration of Aspcl cells. Furthermore, PAM treatment increased the accumulation of reactive oxygen species (ROS) and reduced the mitochondrial membrane potential in Aspcl cells. In addition, PAM treatment down-regulated the AKT serine/threonine kinase 1/signal transducer and activator of transcription 3 signaling pathway and induced ROSdependent cellular autophagy. Conclusion: Our findings suggest that PAM can induce apoptosis of Aspcl cells through ROS-dependent autophagy and may be a candidate for use in pancreatic cancer therapeutics.
\end{abstract}

This article is freely accessible online.

*These Authors contributed equally to this work.

Correspondence to: Dong-sun Lee, Department of Biotechnology, College of Applied Life Science, Jeju National University, Jeju, Republic of Korea. Tel.: +82 647543340, Fax: +82 647513780, e-mail: dongsunlee@jejunu.ac.kr

Key Words: Non-thermal plasma, apoptosis, pancreatic cancer, reactive oxygen species, autophagy.
Pancreatic cancer is one of the most aggressive and lethal malignant adenocarcinomas, with a 5-year survival rate of only 7\% (1-3). The tumor microenvironment in pancreatic cancer is dynamically changing; this complex environment promotes tumor development, metabolism and therapeutic resistance (4). Because of its aggressive growth, pancreatic cancer can invade tissues, escape from chemotherapy and cannot be surgically removed (5). Therapeutic agents that are utilized through systemic injections are gemcitabine and 5fluorouracil; however, they induce several side-effects and fail to satisfactorily prolong survival (6). Therefore, the development of novel and efficient pancreatic cancer therapies that induce fewer toxic effects is of great importance.

Non-thermal dielectric barrier discharge plasma (NTP) is an ionized gas produced by applying high voltage between a dielectric-covered electrode and a biological target. Our previous studies have shown that the application of nonthermal argon gas plasma under appropriate conditions can effectively optimize the germination rate of soybeans (7), the development of chicken embryos (8), the growth of chickens (9) and the quality of sperm (10) by regulating redox homeostasis, energy metabolism and DNA methylation. Recently, due to its stability, low cost, and easy application to targeted tissues with excellent effect, a plasma-activated solution [mainly including plasma-activated water and plasma-activated medium without cells (PAM)] has been applied to various cancer cell lines, including those of glioblastoma (11), colon cancer (12), and breast cancer and lung cancer (13).

PAM therapy plays an important role in anticancer effects through cellular signal pathways, depending on the type of cancer (14). Reactive oxygen species (ROS), hydrogen peroxide $\left(\mathrm{H}_{2} \mathrm{O}_{2}\right)$, nitrate $\left(\mathrm{NO}_{3}{ }^{-}\right)$and nitrite $\left(\mathrm{NO}_{2}{ }^{-}\right)$in PAM are assumed to be mostly stable under appropriate conditions and are the main factors inducing cancer cytotoxicity. Since 
the anticancer effects of ROS generated by NTP can target cancer cells, NTP would be an effective means of induction for immunogenic cell death $(15,16)$. NTP treatment of CT26 colorectal cancer cells induced T-cell responses through targeting guanylyl cyclase C (17). In glioblastoma cells, PAM with high concentrations of $\mathrm{H}_{2} \mathrm{O}_{2}$ and $\mathrm{NO}_{2}$ induced down-regulation of the AKT and extracellular signalregulated kinase (ERK) signaling pathways, inhibition of the glycolysis pathway and enhancement of the pentose phosphate pathway $(11,18)$. Prostate cancer cells, with a background of high energy metabolism and higher oxidative conditions, cause them to be more vulnerable to plasmainduced injury (19). The growth of human colorectal tumor spheroids treated with PAM in vitro was inhibited through ATP depletion, mitochondrial oxidative stress, necrosis and apoptosis (12). Tumors induced in vivo from murine pancreatic cancer cell line 6606PDA were significantly reduced by PAM and showed large areas of cells undergoing apoptosis (5). It has been demonstrated that NTP acts as a cellular stressor in mesothelioma cells by stimulating ROS generation and autophagy (20).

Autophagy is a self-digestion mechanism that has been interpreted as a double-edged sword when applied to cancer cells and is attributed to both tumor-suppressing andpromoting functions (21). The tumor-suppressive function of autophagy occurs through cellular homeostasis and related processes by enabling pre-malignant cells to escape genotoxic stress and inflammation (22), inhibiting the epithelial-tomesenchymal transition and suppressing migration $(23,24)$. However, the role of autophagy in plasma-induced pancreatic cancer cell apoptosis is not fully understood

In this study, we investigated the antitumor effects of PAM on pancreatic cancer cells and explain its mechanism of action.

\section{Materials and Methods}

Cell culture and media. Aspc1 Human pancreatic cancer cells, NIH3T3 mouse fibroblasts and 293T human renal epithelial cells were obtained from the American Type Culture Collection (Manassas, VA, USA). NIH3T3 and 293T cells were cultured in Dulbecco's modified Eagle's medium (Gibco, Waltham, MA, USA). Aspc1 cells were cultured in RPMI 1640 medium (Gibco). The medium contained $10 \%$ fetal bovine serum (FBS; Welgene, Daegu, Republic of Korea) and 1\% penicillin (Invitrogen). The cells were maintained at $37^{\circ} \mathrm{C}$ in a humidified incubator with $5 \% \mathrm{CO}_{2}$.

PAM treatment and $N$-acetyl cysteine (NAC) treatment. PAM was generated by the exposure of $10 \mathrm{ml}$ cell culture medium in a 100 $\mathrm{mm}$ petri dish to a nonthermal dielectric barrier discharge plasma reactor (Figure 1A) following the working principle from our previously reported experiments $(7,8,21)$. This process enabled the exposure of the medium to plasma for various periods $(16.4 \mathrm{kV}$ for $30,60,120,180 \mathrm{~s})$ or voltage $(11.7,16.4,22.0$, and $25.5 \mathrm{kV}$ for 120 s). The dishes with PAM were then returned to the incubator for 2 $\mathrm{h}$ before use. Cells not exposed to PAM were used as the control group. All instances of PAM exposure were performed under the same experimental conditions (gas flow at $2 \mathrm{l} / \mathrm{min}$, exposure frequency, applied voltage, and pulse duration) and with the same distance maintained between the tip of electrode needles and the upper surface of the medium $(20 \mathrm{~mm})$. Fresh PAM was prepared for the experiments. After PAM treatment, we added $2.5 \mathrm{mM}$ of NAC into the culture medium.

Cell viability assay. Cells were seeded in 96-well plates at $1 \times 10^{4}$ cells/well, cultured for $24 \mathrm{~h}$ and then incubated for $24 \mathrm{~h}$ with PAM generated at different doses. Cell viability was assayed following the manufacturer's protocol for EZ-Cytox (DoGenBio, Seoul, Republic of Korea) by adding $10 \mu$ l of EZ-Cytox to each well, and incubating the plates at $37^{\circ} \mathrm{C}$ for $1 \mathrm{~h}$. The OD was measured using a GloMax ${ }^{\circledR}$ Explorer Multimode microplate reader (Promega, Madison, WI, USA) at a wavelength of $450 \mathrm{~nm}$. Cell viability was calculated as (OD under treatment/OD vehicle control group) $\times 100 \%$.

Cell apoptosis assay. Annexin V-phycoerythrin staining was used to analyze cell apoptosis. Aspc1 cells were collected after treatment for $6 \mathrm{~h}$ with PAM generated at different doses $(16.4 \mathrm{kV}$ for 30,60 and $120 \mathrm{~s})$. The Aspc1 cells were washed with phosphate-buffered saline (PBS) twice and fixed with $195 \mu$ l of $1 \times$ binding buffer, followed by the addition of $5 \mu \mathrm{l}$ of annexin V from an Annexin VPE apoptosis detection kit (BD (BD Biosciences, San Jose, CA, USA). After $20 \mathrm{~min}$ of incubation in the dark, PBS was added to bring the total volume to $500 \mu \mathrm{l}$. A fluorescence microscope (Olympus IX70; Olympus, Tokyo, Japan) and a BD AccuriTM C6 flow cytometer (BD Biosciences, CA, USA) were used to analyze cell apoptosis. Fluorescence intensities were analyzed using ImageJ software (NIH, Bethesda, MA, USA).

Caspase activity assay. To assess caspases, Aspc 1 cells were seeded at $1 \times 10^{4}$ cells/well into 96-well plates and cultured with PAM, and the caspase $3 / 7$ activities were estimated using Caspase-Glo ${ }^{\circledR} 3 / 7$ assay kits (Promega, Madison, WI, USA) and measuring the luminescence. The contents of the Caspase-Glo ${ }^{\circledR}$ 3/7 assay kits (Promega, USA), provided in lyophilized form, were converted into a working solution, and $100 \mu \mathrm{l}$ of working reagent was added to each well, and the plates were incubated for an additional $30 \mathrm{~min}$ at room temperature. The luminescence levels were evaluated for the control, PAM-treated, and NAC-PAM treated groups.

Colony-formation assay. Aspc 1 cells $\left(1 \times 10^{3}\right.$ cells/well $)$ were seeded in six-well plates, treated with PAM $(16.4 \mathrm{kV}-120 \mathrm{~s})$ for 1 day and maintained at $37^{\circ} \mathrm{C}$ in a $5 \% \mathrm{CO}_{2}$ incubator for 7 days. The cells were then washed with $1 \times$ PBS, fixed for 10 min with $3.7 \%$ formaldehyde, treated for $20 \mathrm{~min}$ with methanol, and stained for 30 min with $0.05 \%$ crystal violet. The plates were washed with $1 \times$ PBS three times prior to image capturing (22). Colony formation was calculated as (number of colonies formed under treatment/number of colonies formed by vehicle control group) $\times 100 \%$.

Sphere-formation assay. Aspc1 cells $\left(2 \times 10^{3}\right.$ cells/well $)$ were seeded in a 6-well Ultra Low Cluster plate (Corning, Waltham, MA, USA) and cultured for 7 days in suspension in serum-free Dulbecco's modified Eagle's medium/F12 (Gibco) containing 2\% B27 (supporter of neuron growth; Invitrogen), $10 \mathrm{ng} / \mathrm{ml}$ epidermal 
growth factor (Calbiochem, Kenilworth, NJ, USA), $20 \mathrm{ng} / \mathrm{ml}$ basic fibroblast growth factor (KOMA Biotech, Seoul, Korea) and $1 \%$ penicillin (Invitrogen, Waltham, MA, USA) with and without PAM treatment. An inverted microscope was used to image the spheres. Sphere-formation efficiency was calculated as the percentage of spheres formed by the PAM-treated group relative to that of control group (23) after 7 days.

Wound-healing assay. Aspc1 cells were seeded into IncuCyte ImageLock 96-well microplates at $1 \times 10^{6}$ cells/well without PAM. A linear scratch in the cell monolayer was made by a wound maker (Essen Bioscience, Ann Arbor, MI, USA). The cells were rinsed with $1 \times$ PBS three times and PAM $(16.4 \mathrm{kV}-120 \mathrm{~s})$ was added. Photomicrographs of the cells were taken at 0 and $48 \mathrm{~h}$ using an IncuCyte Live-Cell analysis system (Essen Bioscience, Ann Arbor, Michigan, USA). Wound healing area $=($ scratch area under treatment/scratch area of the control group) $\times 100 \%$.

Cell migration assay. Migration assays were performed using 24 well chambers with $8 \mu \mathrm{m}$ pore polycarbonate membranes (Merck Millipore, Darmstadt, Germany). Two hundred microliters of Aspc1 cell suspension in medium containing $0.5 \%$ FBS with PAM was added separately to the upper chamber $\left(2 \times 10^{5}\right.$ cells/chamber $)$. In each case, the bottom chamber was filled with $800 \mu$ l of medium supplemented with $20 \%$ FBS as a chemoattractant. The cells were then incubated for $96 \mathrm{~h}$ at $37^{\circ} \mathrm{C}$ in $5 \% \mathrm{CO}_{2}$. The cells that passed through the coated membrane to the lower surface were then fixed with $3.7 \%$ paraformaldehyde and stained with $0.05 \%$ crystal violet for $1 \mathrm{~h}$. Images were captured using a microscope $(22,23)$. Cell migration $=($ number of migrated cells under treatment/number of migrated cells without PAM) $\times 100 \%$.

ROS production analysis. Mitochondrial superoxide was detected by MitoSOX Red (Thermo Fisher Scientific, Waltham, MA, USA), and 2',7'-dichlorofluorescein diacetate (DCF-DA) dye (Sigma-Aldrich, St. Louis, MO, USA) was used to detect intracellular ROS production following the manufacturers' protocols. Aspc1 cells with/without PAM treatment were stained with $10 \mu \mathrm{M}$ DCF-DA for $15 \mathrm{~min}$ and $5 \mu \mathrm{M}$ MitoSOX Red for 10 min at $37^{\circ} \mathrm{C}$ in an incubator. A fluorescence microscope was used to take images of the Aspc1 cells. Fluorescence intensities were analyzed using ImageJ software. ROS accumulation was measured using flow cytometry.

Cell mitochondrial membrane. JC-1 dye (Sigma-Aldrich, St. Louis, MI, USA) was used to detect the cell mitochondrial membrane potential. Aspc1 cells with/without PAM treatment were washed with PBS and stained with $2 \mu \mathrm{g} / \mathrm{ml}$ of JC- 1 dye for $30 \mathrm{~min}$ at $37^{\circ} \mathrm{C}$. Images were taken using a fluorescence microscope. Fluorescence intensities were analyzed using ImageJ software.

Immunocytochemistry assay. Aspc 1 cells with/without PAM treatment were fixed for 10 min with $3.7 \%$ formaldehyde and incubated in $1 \%$ bovine serum albumin as a blocking buffer for $1 \mathrm{~h}$ at room temperature. The cells were incubated with primary antibodies against light chain 3 alpha/beta (LC3A/B) (1:200; Cell signaling, Danvers, MA, USA) diluted in blocking buffer at $4{ }^{\circ} \mathrm{C}$ overnight and then stained with rabbit IgG-PE red fluorescent secondary antibody. Nuclei were stained with DAPI for $15 \mathrm{~min}$. Images were taken using a fluorescence microscope.
Western blotting analysis. Cell lysis buffer was used for a $30 \mathrm{~min}$ extraction to extract cell proteins from Aspc1 cells with/without PAM treatment, which were then centrifuged. Protein samples $(20 \mu \mathrm{g} / 10 \mu \mathrm{l})$ were loaded and run onto a gel, which was transferred onto a nitrocellulose membrane (BIO-RAD, Hercules, CA, USA). The membrane was incubated in blocking solution ( $2 \%$ bovine serum albumin) at room temperature for $60 \mathrm{~min}$ and treated with primary antibodies against BCL2 apoptosis regulator (BCL2), poly (ADPribose) polymerase (PARP), glyceraldehyde 3-phosphate dehydrogenase, AKT serine/threonine kinase 1 (AKT), p-AKT, signal transducer and activator of transcription 3 (STAT3), p-STAT3, octamer-binding transcription factor 4 (OCT4), p-ERK, ERK (AbFrontier, Seoul, Republic of Korea); NANOG (Santa Cruz Biotechnology, Dallas, TX, USA); caspase-3 (Abcam, Cambridge, MA, USA); interleukin 6 (IL6; Bioss, Woburn, MA, USA); and LC3A/B (Cell Signaling Technology, Danvers, MA, USA) at $4^{\circ} \mathrm{C}$ overnight. The membranes were then incubated with mouse IgG (Vector Labs, Burlingame, CA, USA) or goat anti-rabbit IgG (Vector Labs) at room temperature for $6 \mathrm{~h}$ and washed with Tris-buffered saline, and Pierce ECL Western blotting substrate (Thermo Fisher Scientific) was used to visualize the protein bands. The bands were captured using an ImageQuant ${ }^{\mathrm{TM}}$ LAS 4000 mini Fujifilm camera (GE Healthcare, Chicago, IL, USA).

Statistical analysis. Data are presented as the mean \pm standard deviation (SD) of three independent experiments. Statistically significant differences among treatment groups were determined by one-way ANOVA ( $p<0.05$ was considered to indicate a statistically significant difference) (23). Statistical analysis was performed using the Statistical Package for the Social Sciences (SPSS version 19.0; IBM, Armonk, NY, USA).

\section{Results}

PAM inhibited proliferation and induces apoptosis of pancreatic cancer cells. To evaluate whether PAM suppresses pancreatic cancer cells, we applied PAM at various doses and voltages to Aspc1 pancreatic cancer cells using an NTP exposure method (Figure 1A). As shown in Figure 1B and Figure 1F, PAM treatment had an inhibitory effect on the proliferation of Aspc1 cells. The cytotoxic effect induced by PAM in Aspc1 cells not only inhibited proliferation but also reduced the cell population, but this was not the case in NIH3T3 mouse fibroblasts and 293T human renal epithelial cells (Figure 1C). We used $16.4 \mathrm{kV}$ and $120 \mathrm{~s}$ exposure duration of PAM for further analyses of the mechanism of PAM action in Aspc1 cells. PAM treatment induced significant apoptosis (Figure 1D) and reduced BCL2, pro-caspase- 3 and pro-PARP expression in Aspc1 cells (Figure 1E).

PAM suppressed the malignant behavior of Aspcl cells. Malignant cancer cells are characterized by the potential for metastasis and proliferation (24). Compared with the control group, the PAM-treated group showed reduced colonyforming ability in vitro (Figure $2 \mathrm{~A}$ ). We observed reduced self-renewal ability in PAM-treated groups based on the presence of fewer and smaller spheres (Figure 2B). The 


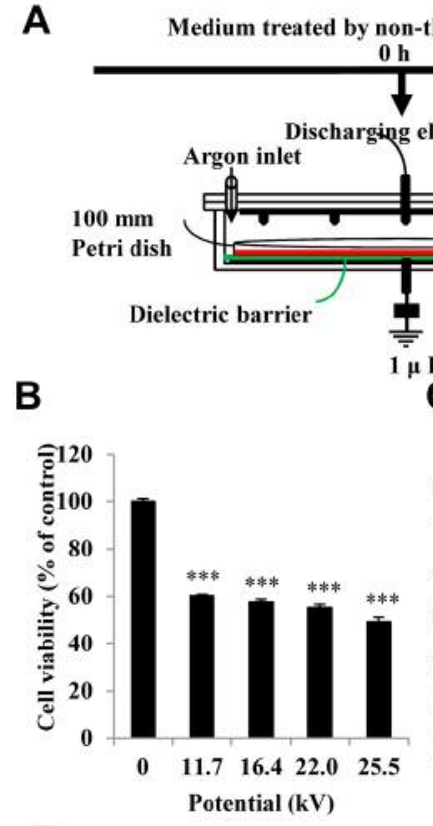

$\mathbf{E}$

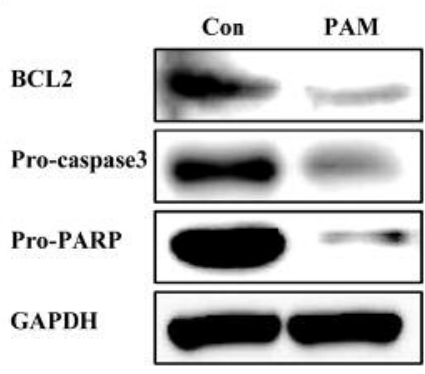

C
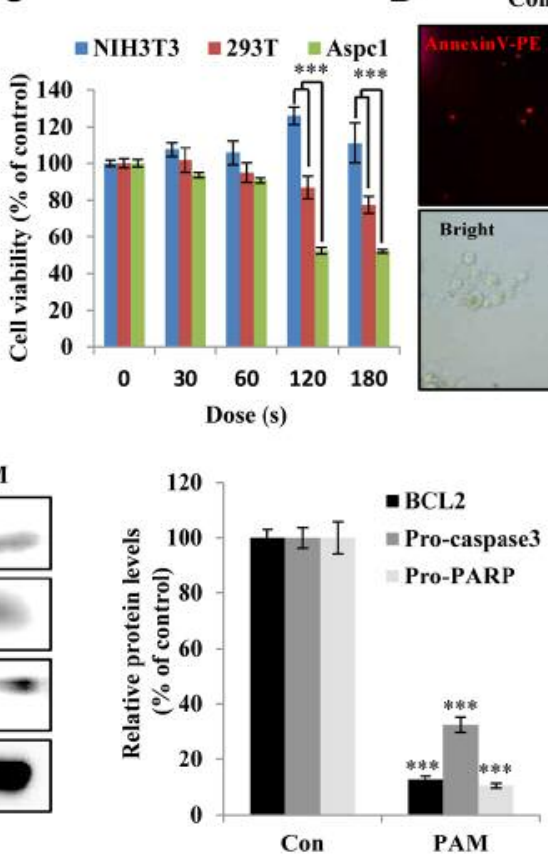

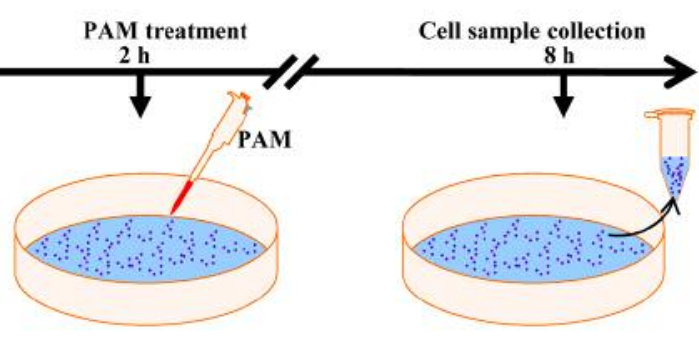

D
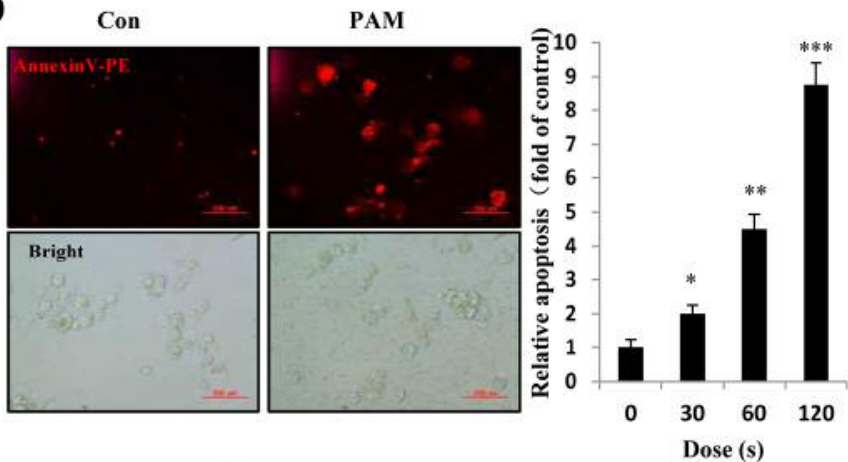

$\mathbf{F}$

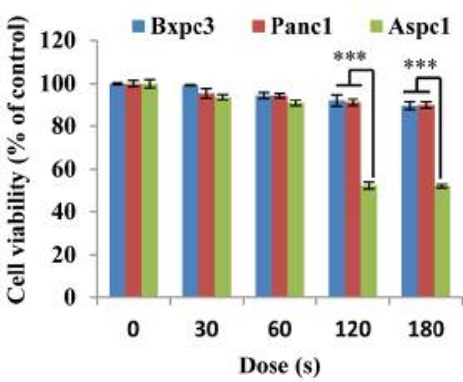

Figure 1. Effect of plasma-activated medium (PAM) on pancreatic cancer cells. A: Timeline for non-thermal PAM treatment experiment. B: Viability of Aspc1 human pancreatic cancer cells treated with PAM of various doses and of various potentials for 24 h. C: The NIH3T3, 293T and Aspc1 cells were treated with PAM in a dose-dependent manner $(16.4 \mathrm{kV})$ for $24 \mathrm{~h}$, and cell viability was measured using an EZ-Cytox kit. D: Apoptotic Aspc1 cells were detected by annexin V-phycoerythrin staining and observed under fluorescence microscopy after 6-h treatment with PAM (16.4 $\mathrm{kV}-120 \mathrm{~s}$ ) (scale bar: $100 \mu \mathrm{m})$; the right side shows the quantified fluorescence intensity after treatment with PAM in a dose-dependent manner. E: Western blot of apoptosis-related proteins BCL2 apoptosis regulator (BCL2), pro-caspase-3 and pro poly (ADP-ribose) polymerase (PARP) in Aspc1 cells after 6-h treatment with PAM (16.4 kV-120 s). GAPDH: glyceraldehyde 3-phosphate dehydrogenase. F: The cell viability of human pancreatic cancer Bxpc3, Pancl and Aspcl cells were treated with a dose-dependent PAM (16.4 kV) for $24 \mathrm{~h}$. Quantified data are presented as the mean $\pm S D$ of three independent experiments. Significantly different at $* p<0.05 ; * * p<0.01 ; * * *<<0.001$ vs. the control (Con).

wound-healing ability of PAM-treated Aspc1 cells was inhibited (Figure 2C). The cell migration of Aspc1 cells was examined to determine their ability for cancer metastasis; PAM treatment reduced cell migration, indicating reduced metastatic capacity (Figure 2D). The expression of IL6, OCT4, and NANOG proteins was reduced, whilst that of Ecadherin was increased by PAM (Figure 2E).

PAM induced ROS accumulation and loss of mitochondrial membrane potential in Aspcl cells. To consider the effect of
PAM-induced ROS accumulation, we examined ROS generation in Aspc1 cells after PAM treatment using DCFDA and MitoSOX Red. PAM increased not only the intracellular ROS level (Figure 3A: dose-dependent increase in DCF-DA fluorescence intensity) but also the superoxide level in the mitochondria (Figure 3B: increased MitoSOX fluorescence intensity). Loss of mitochondrial membrane potential is usually observed in mitochondrial damage, early cell apoptosis and mitophagy (autophagy initiated for degradation of damaged mitochondria) (25). Compared with 

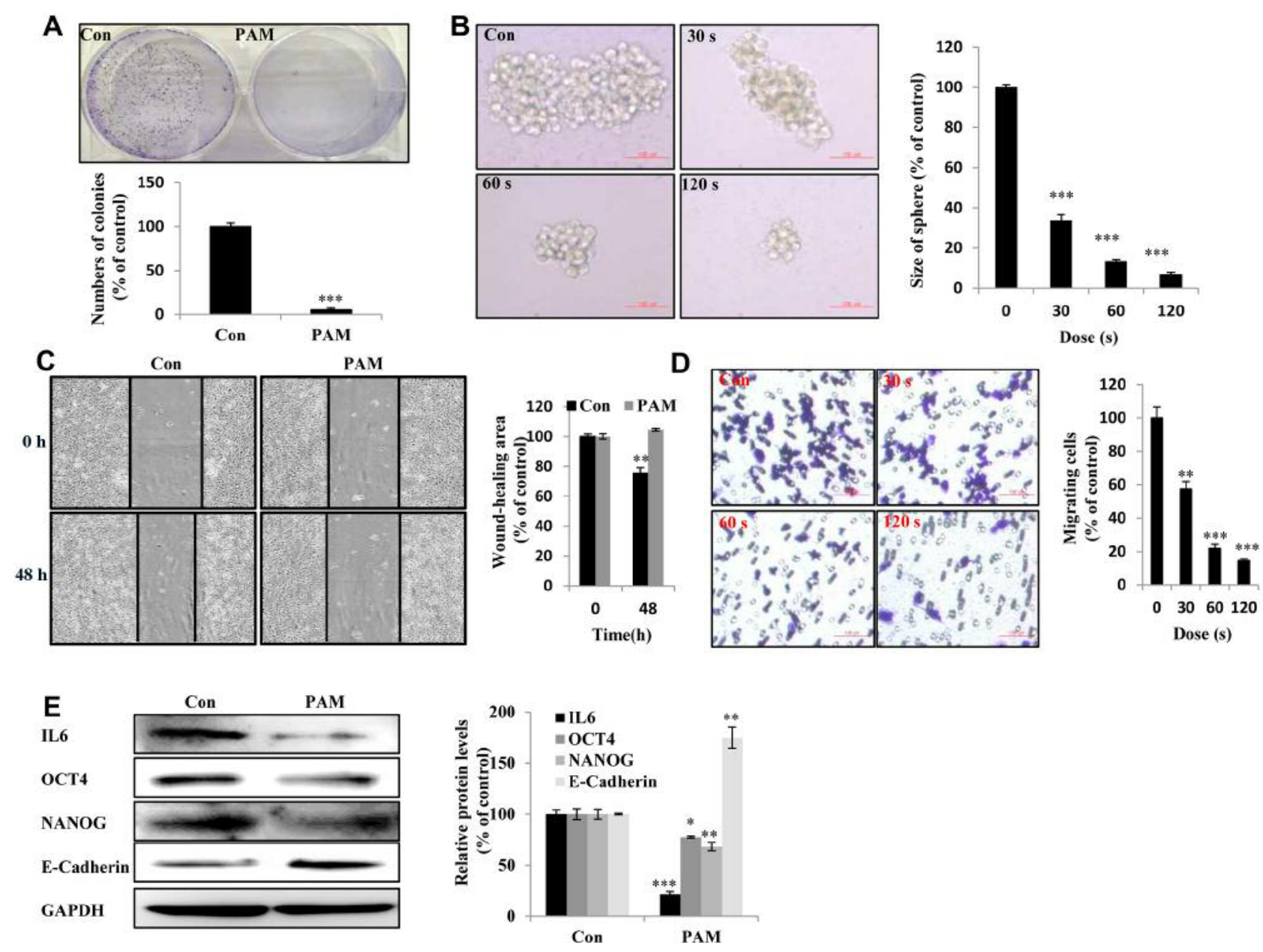

Figure 2. Plasma-activated medium (PAM) suppresses the malignancy of Aspc1 cells. A: The day after cancer cells had attached to the bottom of plates and the medium was removed and PAM added. Upper panel: The colony-forming ability in Aspc1 cells exposed to PAM (16.4 kV-120 s) for 7 days as detected by colony-formation assay; lower panel: quantification of colony-formation data. B: The sphere-forming ability of Aspcl cells

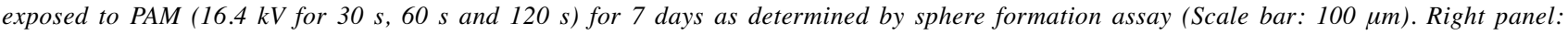
quantification of size of colonies. C: Wound-healing assay. Left: image; right: quantification of wound healing area. D: Transwell assay Left: image; right: quantification of cell migration ability (scale bar: $100 \mu \mathrm{m})$. E: Levels of interleukin 6 (IL6), octamer-binding transcription factor 4 (OCT4), NANOG, and E-cadherin proteins in Aspc1 cells after 6-h treatment with PAM (16.4 kV-120 s) as measured using western blot. The data are presented as the mean $\pm S D$ of three independent experiments. Significantly different at $* p<0.05 ; * * p<0.01 ; * * * p<0.001$ vs. the control (Con).

the control group, PAM-exposed Aspc1 cells displayed reduced red fluorescence intensity and increased green fluorescence intensity (Figure 3C), which indicated that PAM induced mitochondrial-related cell death.

PAM-induced accumulated ROS participate in the apoptosis of Aspcl cells via the STAT3 and AKT signaling pathways. Pretreatment with NAC significantly inhibited PAM-induced cell death (Figure 4A). In addition, NAC reversed PAMinduced increase in intracellular ROS (Figure 4B) and caspase-3/7 activities (Figure 4C). Pretreatment with NAC reversed the PAM-induced decrease in p-AKT and p-STAT3 expression (Figure 4D), showing that PAM regulates the AKT and STAT3 signaling pathways.

PAM-induced ROS led to autophagic cell death of Aspcl cells. We found that Aspc1 cells showed obvious morphological changes after PAM treatment and formation of vesicles such as autophagosomes (Figure 5A). To directly assess the level of autophagy, we examined the expression of LC3A/B, a classical marker of autophagosome formation. As shown in Figure 5B, the expression of LC3A/B was indicated by a significant 

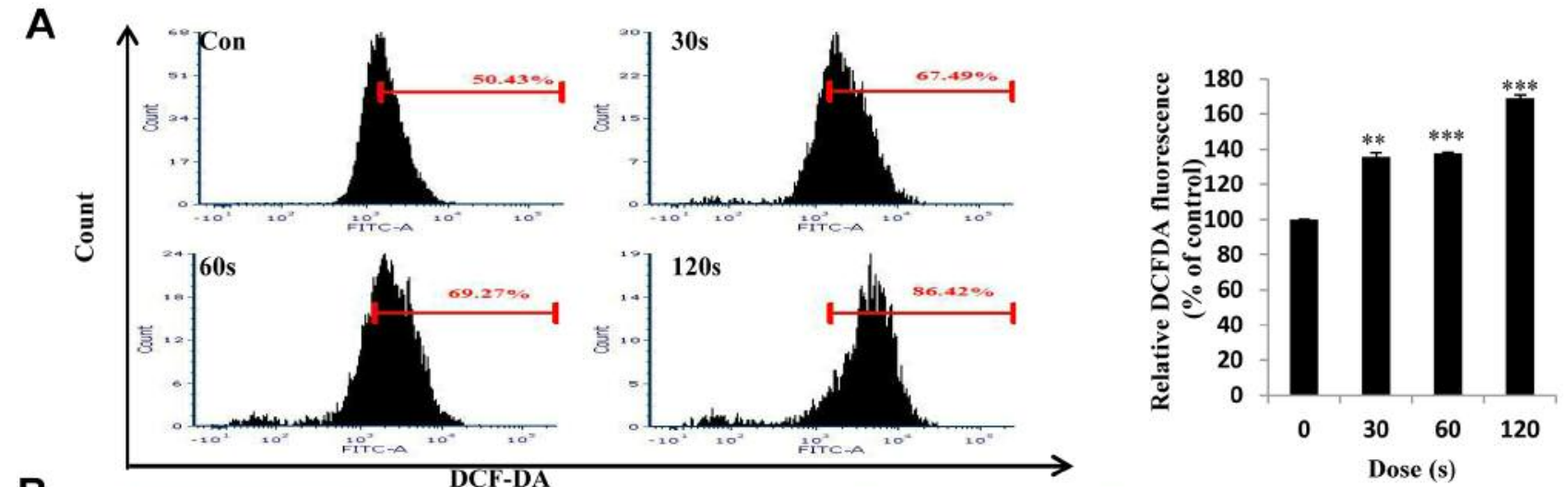

B
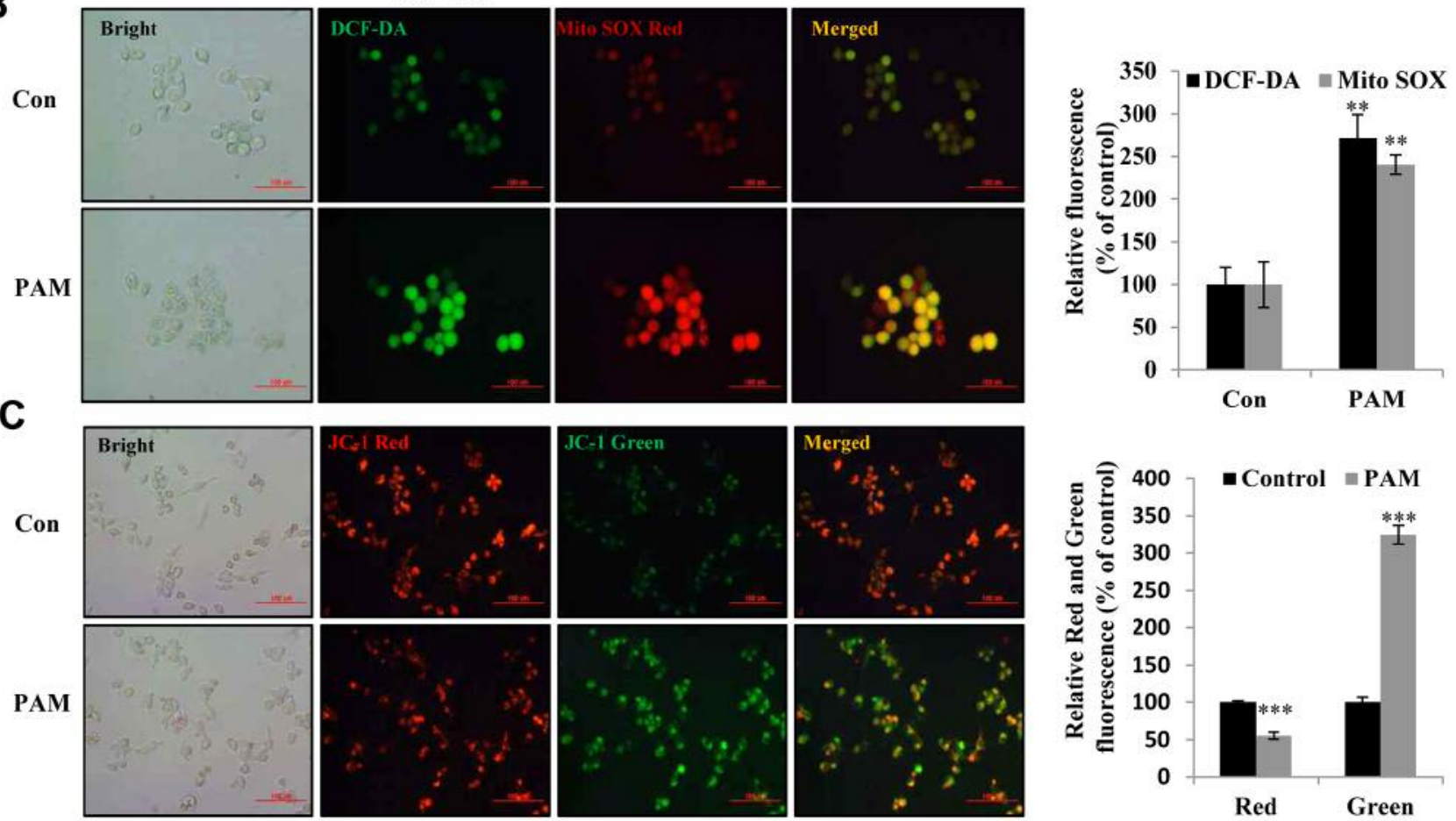

Figure 3. Intracellular reactive oxygen species (ROS) production and mitochondrial membrane potential induced by plasma-activated medium (PAM) in Aspc1 cells. A: Flow cytometric analysis of intracellular ROS production in Aspc1 cells using 2',7'-dichlorofluorescein diacetate (DCF-DA; 10 $\mu M$ )-exposed PAM (16.4 kV-30 s, $60 \mathrm{~s}$ and $120 \mathrm{~s})$ for $6 \mathrm{~h}$. Right: Quantity of ROS in A. B: Imaging of Aspc1 cells exposed to PAM (16.4 kV-120 s) for $6 \mathrm{~h}$ then stained with DCF-DA and MitoSOX. DCF-DA: Green fluorescence; MitoSOX Red: red fluorescence (Scale bar: $100 \mu \mathrm{m}$ ). Right side is relative fluorescence intensity for DCF-DA and Mito Sox Red staining in B. C: Imaging of Aspcl cells exposed to PAM (16.4 kV-120 s) for $6 \mathrm{~h}$ stained with JC-1 (scale bar: $100 \mu \mathrm{m})$. The right side is the relative fluorescence intensity for JC-1 staining in $C$. The data are represented as the mean $\pm S D$ of three independent experiments. Significantly different at $* * p<0.01 ; * * * p<0.001 \mathrm{vs}$. the control (Con).

increase in red fluorescence after PAM treatment. To quantitatively evaluate autophagy, western blotting was performed to determine the level of p-ERK kinase, which is involved in beclin-1-related autophagy and mitophagy $(26,27)$, and LC3A/B level. PAM treatment significantly increased the levels of p-ERK and LC3A/B, and its effects were abrogated in cells pretreated with NAC (Figure 5C).

\section{Discussion}

Because of the highly aggressive phenotype and chemoresistance of pancreatic cancer, therapeutic options are limited (28). Recently, chemotherapy using gemcitabinebased combination therapy was adopted to increase survival rates and improve patients' quality of life, but limited 
A

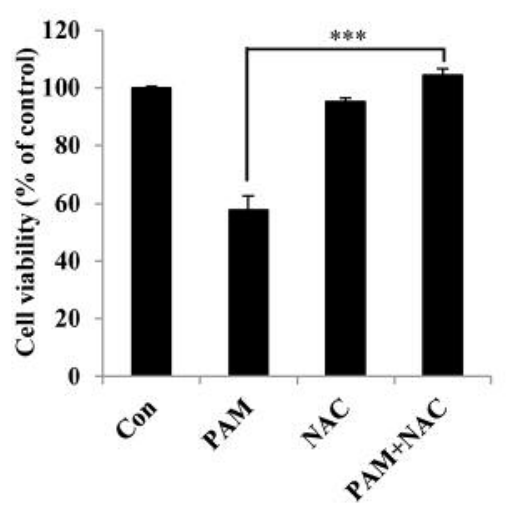

D

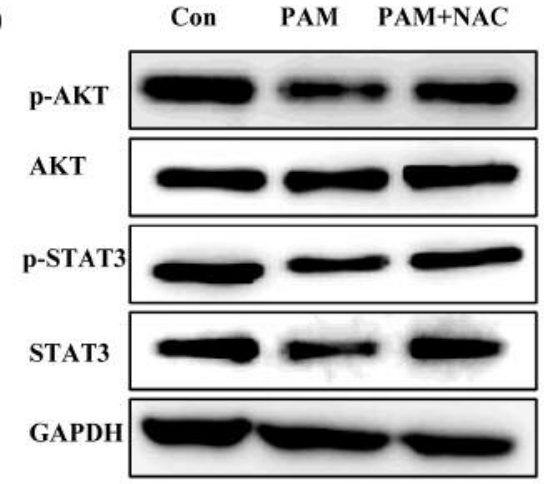

B
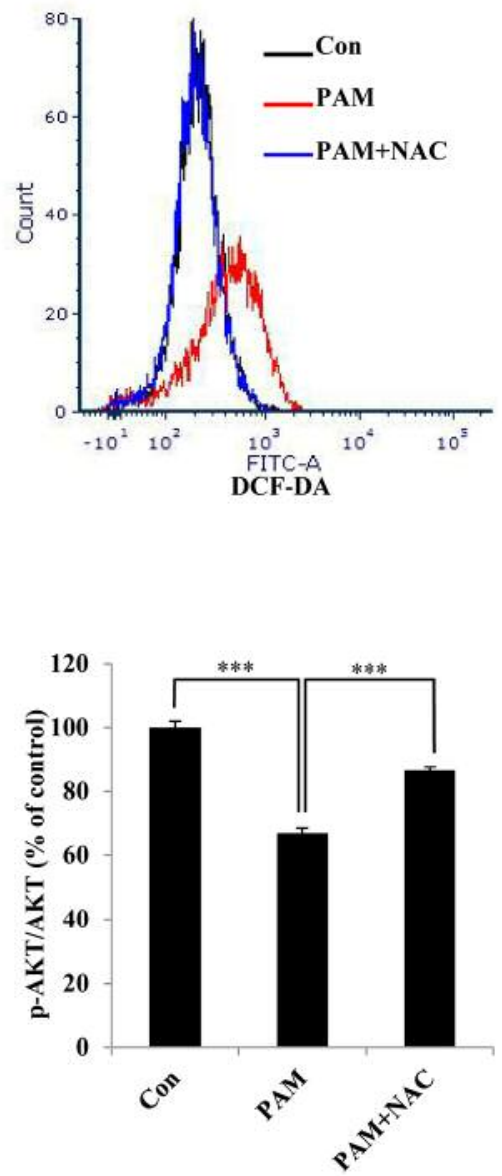

C
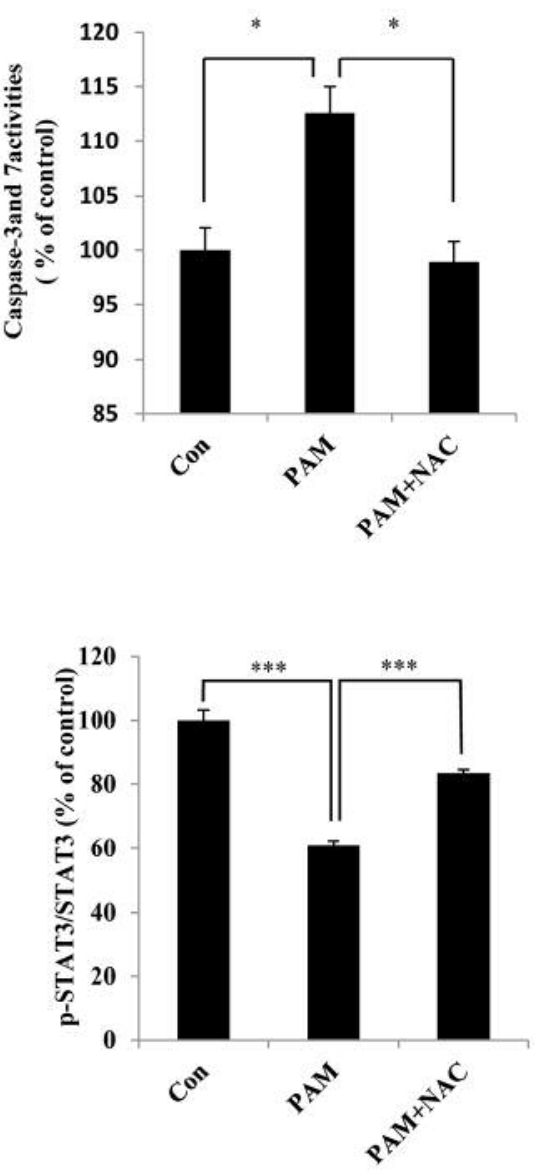

Figure 4. Plasma-activated medium (PAM)-induced reactive oxygen species (ROS) participate in the apoptosis of Aspc1 cells. A: The viability of Aspc1 cells treated with/without PAM (16.4 kV-120 s) for $24 \mathrm{~h} . P A M$, and N-acetyl cysteine (NAC) added to PAM were left in a water bath at $37^{\circ} \mathrm{C}$ for $30 \mathrm{~min}$ before being used to treat Aspc1 cells. B: Flow cytometric analysis of ROS generation in Aspc1 cells exposed to PAM (16.4 kV-120 s) with and without NAC for $6 \mathrm{~h}$. C: Caspase-3 and-7 activities in Aspcl cells treated with PAM (16.4 kV-120 s) with and without NAC for 6 h. D: Western blot analysis was performed to check the expression of signal transducer and activator of transcription 3 (STAT3), p-STAT3, AKT serine/threonine kinase 1 (AKT) and p-AKT, in Aspcl cells treated with PAM (16.4 kV-120 s) with and without NAC for 6 h. The data are represented as the mean $\pm S D$ of three independent experiments. Significantly different at $* p<0.05$; $* * p<0.001$ vs. the control (Con).

rewards and multitudinous side-effects have been the result (29). NTP has been identified as an innovative anticancer approach that directly induces apoptosis, autophagy and immunogenic cell death (16). It seems reasonable to use appropriate conditional PAM for its lethal effect on pancreatic cancer cells.

In this study, our results provide evidence for PAM having antitumor effects on pancreatic cancer cells: i) PAM inhibited malignant cell proliferation and was more cytotoxic to human pancreatic cancer cells than to NIH3T3 mouse fibroblasts and 293T human renal epithelial cells (Figure 1). ii) PAM inhibited colony-and sphere-formation ability and the migration of cancer cells (Figure 2). iii) PAM inhibited cancer cells through ROS accumulation and reduced the mitochondrial membrane potential (Figure 3). Iv) PAMinduced inhibition of cancer cell growth was ameliorated by NAC (Figure 4). v) PAM inhibited the AKT/STAT3 signaling pathway associated with cell survival (Figure 4), stemness and the EMT signaling, specifically reducing the level of IL6, an important cancer cell survival cytokine (Figure 2) (30). vi) PAM induced apoptosis of cancer cells through the ROS-dependent autophagy pathway (Figure 5).

PAM induced expression of E-cadherin protein (Figure $2 \mathrm{E})$. Further study of the transcription factors regulating gene regulation of E-cadherin is needed. Our data showed that generation of ROS by PAM down-regulated expression of 
A

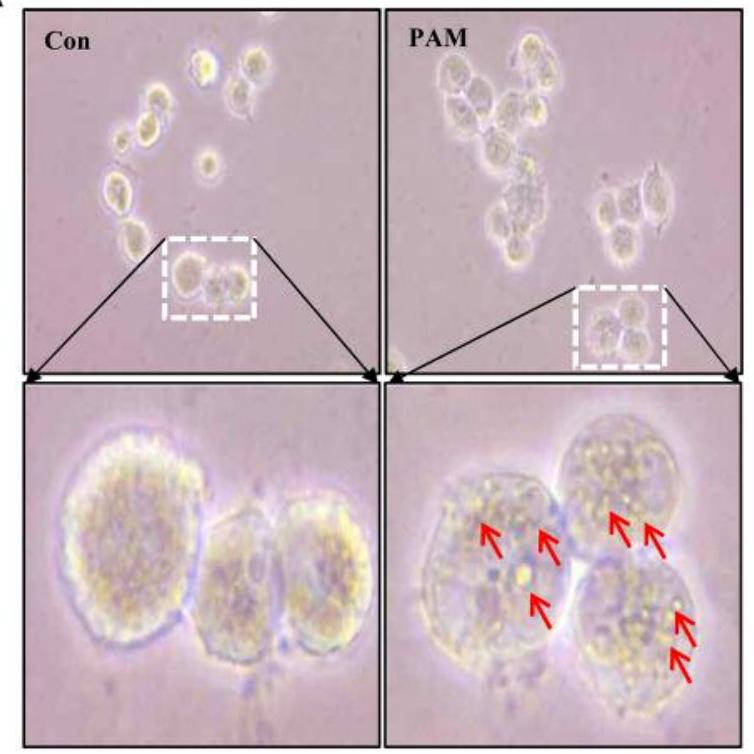

B

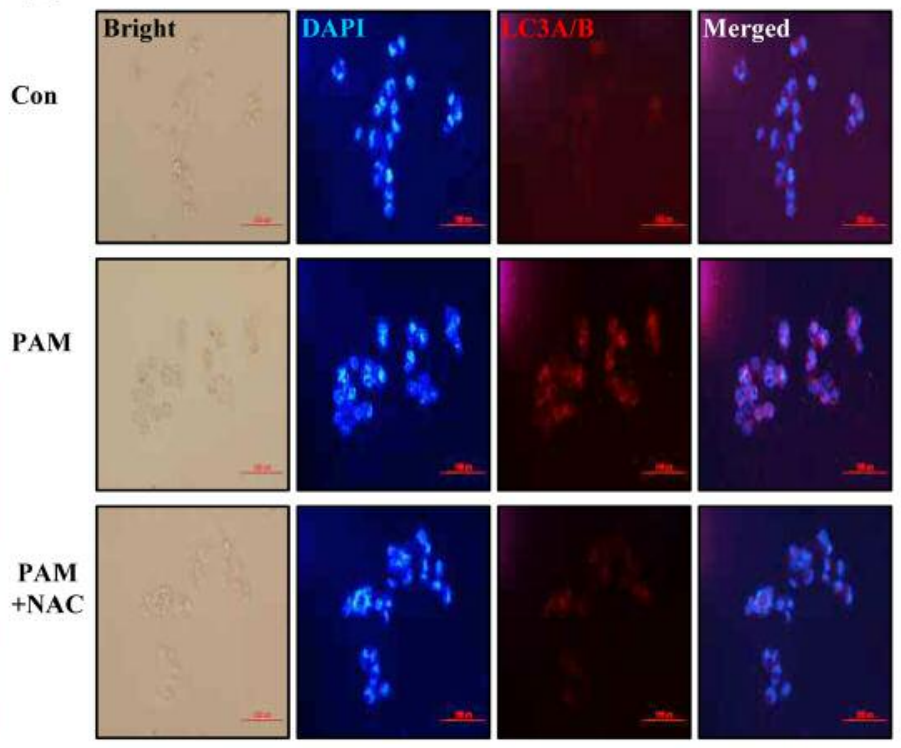

C
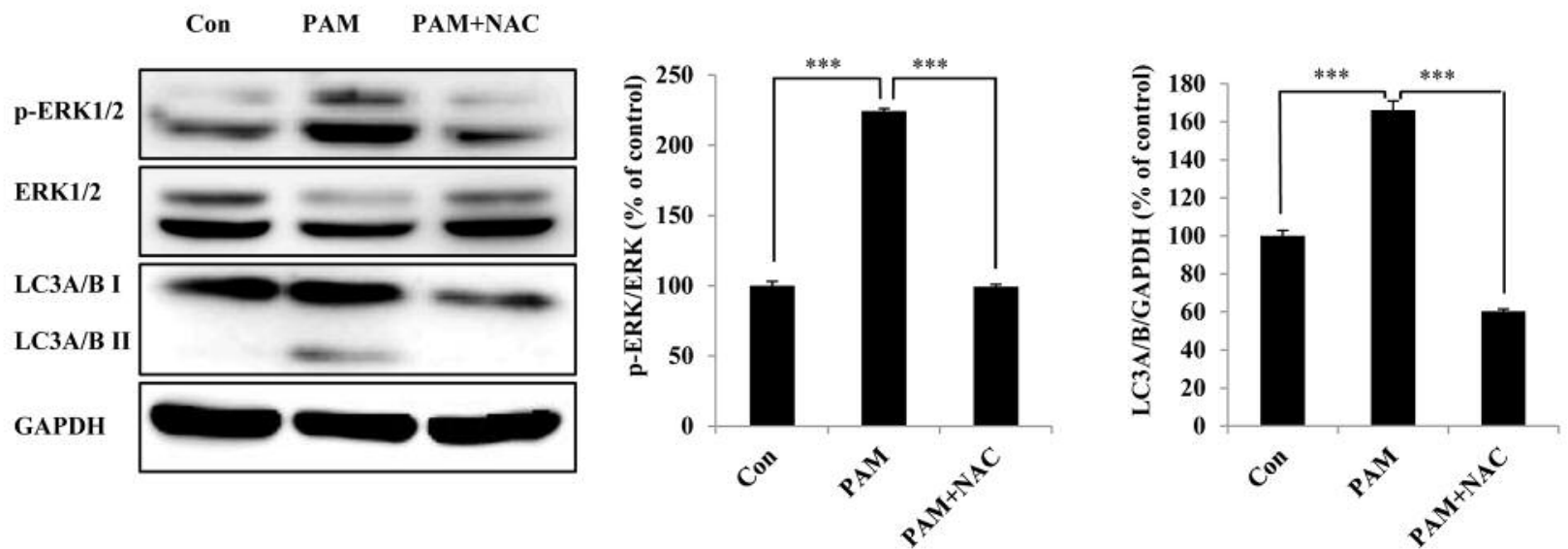

Figure 5. Plasma-activated medium (PAM) induces autophagic cell death of Aspc1 cells by reactive oxygen species (ROS). A: Imaging of morphology of Aspcl cells exposed to PAM (16.4 kV-120 s) for $6 \mathrm{~h}$ (scale bar: $200 \mu \mathrm{m})$. Arrows: Microbubble structures. B: Immunocytochemistry assay of autophagy-associated protein light chain 3 alpha/beta $(L C 3 A / B)$ in Aspcl cells treated with PAM (16.4 kV-120 s) with and without N-acetyl cysteine (NAC) for $6 \mathrm{~h}$ (scale bar: $100 \mu \mathrm{m})$. C: Western blot analysis was performed to check the expression of p-extracellular-regulated kinase (ERK), pERK and LC3A/B in Aspc1 cells treated with PAM (16.4 kV-120 s) with and without NAC for 6 h. GAPDH: glyceraldehyde 3-phosphate dehydrogenase. The data are presented as the mean $\pm S D$ of three independent experiments. ***Significantly different at p<0.001 vs. the control (Con).

BCL2, depolarized the mitochondrial membrane, and activated the caspase cascade, and inducing apoptosis of pancreatic cancer cells. Low levels of ROS induce formation of cancer stem cells (CSCs) (31). The redox regulation of CSC is regarded as a good target for tumor therapy as it is important in the maintenance of CSC. PAM-induced ROS may kill CSCs. PAM displayed a genotoxic effect on human cancer cells, mainly by the production of ROS such as hydrogen peroxide (H2O2) (32). Hydrogen peroxide is well known for its ability to break DNA double strands (12).
In various cancer cells, chemotherapeutic agents induce apoptosis by increasing the level of ROS and activating NADPH oxidase $(33,34)$. Excessive intracellular ROS production damages cellular function proteins and DNA, resulting in mitochondrial dysfunction and even apoptosis $(35,36)$. Recent studies have shown that NTP treatment resulted in time-and dose-dependent ROS accumulation and led to ROS-mediated apoptosis in human liver cancer cells (37). Here, we show that PAM dose-dependently triggered intracellular ROS and mitochondrial superoxide 
accumulation in pancreatic cancer cells (Figure 3A and B). The mitochondrial membrane potential was reduced (Figure 3C), which has been typically observed in mitochondria damage-related early cell apoptosis and mitophagy.

Furthermore, we identified AKT, a mediator of prosurvival proteins (38), as a PAM-induced effector in cancer cells. Additionally, STAT3 is involved in apoptosis, proliferation, invasion, migration and angiogenesis of cancer cells (39). Anticancer agents can reduce the activation of STAT3 and AKT to induce ROS-mediated cell apoptosis (40). Our data indicate that PAM suppressed colony-and sphere-forming ability and cell migration (Figure 2) and reduced the expression of p-AKT and p-STAT3, inhibiting cell proliferation and increasing caspase- 3 and 7 activities, and pre-treatment with the antioxidant NAC inhibited PAMinduced apoptosis and suppressed the inhibition of the AKT and STAT3 signaling pathways (Figure 4).

Mitochondria, as essential energy-producing organelles, concomitantly accumulate ROS, and the degradation process of damaged mitochondria is mediated by mitophagy (41). In autophagy-dependent CD44high/CD24low breast cancer cells, inhibition of autophagy regulates IL6 secretion through the STAT3/JAK2 pathway to induce mammosphere formation (42). Autophagy induced by AZD8055 and rapamycin suppressed glioma-initiating cell self-renewal and tumorigenicity through NOTCH1 degradation (43). Mitochondria-related ROS accumulation induced by NTP results in increased fluid-phase endocytosis and the formation of endosomes and lysosomes (20). Our data showed that PAM led to blocking of the STAT3 signal (Figure 4D). Inhibition of the STAT3 pathway in multiple lung cancer cell lines induced autophagy (44). PAM regulated autophagy through the STAT3 pathway. PAM induced reduction of IL6 protein expression (Figure 2E). The STAT3/IL6 signal pathway has an important role in survival of cells .

We showed that PAM induced the expression of the autophagy marker LC3 (Figure 5), and reduced IL6 protein expression (Figure 2E). PAM induced apoptosis of pancreatic cancer cells through the ROS-dependent autophagy pathway. This study provides encouraging evidence for the role of PAM-conditioned solutions in the treatment of malignant cancer in future clinical therapies.

\section{Conflicts of Interest}

The Authors declare that they have no conflicts of interest in regard to this study.

\section{Authors' Contributions}

Design of the research and experiments: Xing Zhen, Hu-Nan Sun, and Ren Liu; drafting of the article: Hack Sun Choi and Dong-Sun Lee.

\section{Acknowledgements}

This research was supported by the Basic Science Research Program through the National Research Foundation of Korea (NRF) funded by the Ministry of Education (NRF-2016R1A6A1A03012862) and by a project for the Cooperative Research Program for Agriculture Science and Technology Development (PJ01316701), Rural Development Administration, Republic of Korea.

\section{References}

1 Ferlay J, Soerjomataram I, Dikshit R, Eser S, Mathers C, Rebelo M, Parkin DM, Forman D and Bray F: Cancer incidence and mortality worldwide: Sources, methods and major patterns in Globocan 2012. Int J Cancer 136(5): E359-386, 2015. PMID: 25220842. DOI: $10.1002 / \mathrm{ijc} .29210$

2 Siegel RL, Miller KD and Jemal A: Cancer statistics, 2016. CA Cancer J Clin 66(1): 7-30, 2016. PMID: 26742998. DOI: $10.3322 /$ caac 21332

3 Bray F, Ferlay J, Soerjomataram I, Siegel RL, Torre LA and Jemal A: Global cancer statistics 2018: Globocan estimates of incidence and mortality worldwide for 36 cancers in 185 countries. CA Cancer J Clin 68(6): 394-424, 2018. PMID: 30207593. DOI: $10.3322 /$ caac. 21492

4 Neesse A, Bauer CA, Ohlund D, Lauth M, Buchholz M, Michl P, Tuveson DA and Gress TM: Stromal biology and therapy in pancreatic cancer: Ready for clinical translation? Gut 68(1): 159171, 2019. PMID: 30177543. DOI: 10.1136/gutjnl-2018-316451

5 Liedtke KR, Bekeschus S, Kaeding A, Hackbarth C, Kuehn JP, Heidecke CD, von Bernstorff W, von Woedtke T and Partecke LI: Non-thermal plasma-treated solution demonstrates antitumor activity against pancreatic cancer cells in vitro and in vivo. Sci Rep 7(1): 8319, 2017. PMID: 28814809. DOI: 10.1038/s41598017-08560-3

6 Madurantakam Royam M, Ramesh R, Shanker R, Sabarimurugan S, Kumarasamy C, Ramesh N, Gothandam KM, Baxi S, Gupta A, Krishnan S and Jayaraj R: Mirna predictors of pancreatic cancer chemotherapeutic response: A systematic review and meta-analysis. Cancers 11(7), 2019. PMID: 31252688. DOI: $10.3390 /$ cancers 11070900

7 Zhang JJ, Jo JO, Huynh DL, Mongre RK, Ghosh M, Singh AK, Lee SB, Mok YS, Hyuk P and Jeong DK: Growth-inducing effects of argon plasma on soybean sprouts via the regulation of demethylation levels of energy metabolism-related genes. Sci Rep 7: 41917, 2017. PMID: 28167819. DOI: 10.1038/srep41917

8 Zhang JJ, Jo JO, Huynh DL, Ghosh M, Kim N, Lee SB, Lee HK, Mok YS, Kwon T and Jeong DK: Lethality of inappropriate plasma exposure on chicken embryonic development. Oncotarget 8(49): 85642-85654, 2017. PMID: 29156747. DOI: $10.18632 /$ oncotarget.21105

9 Zhang JJ, Wang XZ, Kwon T, Huynh DL, Chandimali N, Kim N, Kang TY, Ghosh M, Gera M, Lee SB, Lee SJ, Lee WS, Kim SB, Mok YS and Jeong DK: Innovative approach of non-thermal plasma application for improving the growth rate in chickens. Int J Mol Sci 19(8), 2018. PMID: 30082605. DOI: 10.3390/ijms19082301

10 Zhang JJ, Chandimali N, Kim N, Kang TY, Kim SB, Kim JS, Wang XZ, Kwon $\mathrm{T}$ and Jeong DK: Demethylation and microRNA differential expression regulate plasma-induced improvement of chicken sperm quality. Sci Rep 9(1): 8865, 2019. PMID: 31222092. DOI: 10.1038/s41598-019-45087-1 
11 Kurake N, Ishikawa K, Tanaka H, Hashizume H, Nakamura K, Kajiyama H, Toyokuni S, Kikkawa F, Mizuno M and Hori M: Non-thermal plasma-activated medium modified metabolomic profiles in the glycolysis of U251SP glioblastoma. Arch Biochem Biophys 662: 83-92, 2019. PMID: 30528778. DOI: 10.1016/j.abb.2018.12.001

12 Chauvin J, Gibot L, Griseti E, Golzio M, Rols MP, Merbahi N and Vicendo P: Elucidation of in vitro cellular steps induced by antitumor treatment with plasma-activated medium. Sci Rep 9(1): 4866, 2019. PMID: 30890760. DOI: 10.1038/s41598-01941408-6

13 Adachi T, Tanaka H, Nonomura S, Hara H, Kondo S and Hori M: Plasma-activated medium induces A549 cell injury via a spiral apoptotic cascade involving the mitochondrial-nuclear network. Free Radic Biol Med 79: 28-44, 2015. PMID: 25433364. DOI: 10.1016/j.freeradbiomed.2014.11.014

14 Kaushik NK, Ghimire B, Li Y, Adhikari M, Veerana M, Kaushik N, Jha N, Adhikari B, Lee SJ, Masur K, von Woedtke T, Weltmann $\mathrm{KD}$ and Choi EH: Biological and medical applications of plasmaactivated media, water and solutions. Biol Chem 400(1): 39-62, 2018. PMID: 30044757. DOI: 10.1515/hsz-2018-0226

15 Khalili M, Daniels L, Lin A, Krebs FC, Snook AE, Bekeschus S, Bowne WB and Miller V: Non-thermal plasma-induced immunogenic cell death in cancer: A topical review. J Phys D Appl Phys 52(42), 2019. PMID: 31485083. DOI: 10.1088/13616463/ab31c1

16 Lin A, Gorbanev Y, De Backer J, Van Loenhout J, Van Boxem W, Lemiere F, Cos P, Dewilde S, Smits E and Bogaerts A: Nonthermal plasma as a unique delivery system of short-lived reactive oxygen and nitrogen species for immunogenic cell death in melanoma cells. Adv Sci 6(6): 1802062, 2019. PMID: 30937272. DOI: $10.1002 /$ advs.201802062

17 Lin AG, Xiang B, Merlino DJ, Baybutt TR, Sahu J, Fridman A, Snook AE and Miller V: Non-thermal plasma induces immunogenic cell death in vivo in murine CT26 colorectal tumors. Oncoimmunology 7(9): e1484978, 2018. PMID: 30228954. DOI: 10.1080/2162402X.2018.1484978

18 Kurake N, Tanaka H, Ishikawa K, Kondo T, Sekine M, Nakamura K, Kajiyama H, Kikkawa F, Mizuno M and Hori M: Cell survival of glioblastoma grown in medium containing hydrogen peroxide and/or nitrite, or in plasma-activated medium. Arch Biochem Biophys 605: 102-108, 2016. PMID: 26820218. DOI: $10.1016 /$ j.abb.2016.01.011

19 Zhunussova A, Vitol EA, Polyak B, Tuleukhanov S, Brooks AD, Sensenig R, Friedman G and Orynbayeva Z: Mitochondriamediated anticancer effects of non-thermal atmospheric plasma. PLoS One 11(6): e0156818, 2016. PMID: 27270230. DOI: 10.1371/journal.pone. 0156818

20 Shi L, Ito F, Wang Y, Okazaki Y, Tanaka H, Mizuno M, Hori M, Hirayama T, Nagasawa H, Richardson DR and Toyokuni S: Non-thermal plasma induces a stress response in mesothelioma cells resulting in increased endocytosis, lysosome biogenesis and autophagy. Free Radic Biol Med 108: 904-917, 2017. PMID: 28465262. DOI: 10.1016/j.freeradbiomed .2017.04.368

21 Zhang JJ, Wang XZ, Luong Do H, Chandimali N, Kang TY, Kim N, Ghosh M, Lee SB, Mok YS, Kim SB, Kwon T and Jeong DK: Microrna-7450 regulates non-thermal plasma-induced chicken Sertoli cell apoptosis via adenosine monophosphateactivated protein kinase activation. Sci Rep 8(1): 8761, 2018. PMID: 29884805. DOI: 10.1038/s41598-018-27123-8
22 Huynh DL, Zhang JJ, Chandimali N, Ghosh M, Gera M, Kim N, Park YH, Kwon T and Jeong DK: SALL4 suppresses reactive oxygen species in pancreatic ductal adenocarcinoma phenotype via FOXM1/PRX 111 axis. Biochem Biophys Res Commun 503(4): 2248-2254, 2018. PMID: 29958885. DOI: $10.1016 /$ j.bbrc.2018.06.145

23 Huynh DL, Koh H, Chandimali N, Zhang JJ, Kim N, Kang TY, Ghosh M, Gera M, Park YH, Kwon T and Jeong DK: Brm270 inhibits the proliferation of $\mathrm{Cd} 44$ positive pancreatic ductal adenocarcinoma cells via downregulation of sonic hedgehog signaling. Evid Based Complement Alternat Med 2019: 8620469, 2019. PMID: 31049070. DOI: 10.1155/2019/8620469

24 Sreepadmanabh M and Toley BJ: Investigations into the cancer stem cell niche using in-vitro 3-D tumor models and microfluidics. Biotechnol Adv 36(4): 1094-1110, 2018. PMID: 29559382. DOI: 10.1016/j.biotechadv.2018.03.009

25 Nazio F, Bordi M, Cianfanelli V, Locatelli F and Cecconi F: Autophagy and cancer stem cells: Molecular mechanisms and therapeutic applications. Cell Death Differ 26(4): 690-702, 2019. PMID: 30728463. DOI: 10.1038/s41418-019-0292-y

26 Zhu JH, Horbinski C, Guo F, Watkins S, Uchiyama Y and Chu CT: Regulation of autophagy by extracellular signal-regulated protein kinases during 1-methyl-4-phenylpyridinium-induced cell death. Am J Pathol 170(1): 75-86, 2007. PMID: 17200184. DOI: 10.2353/ajpath.2007.060524

27 Dagda RK, Zhu J, Kulich SM and Chu CT: Mitochondrially localized erk2 regulates mitophagy and autophagic cell stress: Implications for Parkinson's disease. Autophagy 4(6): 770-782, 2008. PMID: 18594198. DOI: 10.4161/auto.6458

28 Adamska A, Domenichini A and Falasca M: Pancreatic ductal adenocarcinoma: Current and evolving therapies. Int J Mol Sci 18(7), 2017. PMID: 28640192. DOI: 10.3390/ijms 18071338

29 Das S and Batra SK: Pancreatic cancer metastasis: Are we being pre-emted? Curr Pharm Des 21(10): 1249-1255, 2015. PMID: 25506899. DOI: $10.2174 / 1381612821666141211115234$

30 Chong PSY, Zhou J, Lim JSL, Hee YT, Chooi JY, Chung TH, Tan TZ, Zeng Q, Waller DD, Sebag $M$ and Chng WJ: Interleukin-6 promotes a STAT3-PRL3 feedforward loop via SHP2 repression in multiple myeloma. Cancer Res, 2019. PMID: 31337650. DOI: 10.1158/0008-5472.CAN-19-0343

31 Shi X, Zhang Y, Zheng J and Pan J: Reactive oxygen species in cancer stem cells. Antioxid Redox Signal 16(11): 1215-1228, 2012. PMID: 22316005. DOI: 10.1089/ars.2012.4529

32 Judee F, Fongia C, Ducommun B, Yousfi M, Lobjois V and Merbahi N: Short and long time effects of low temperature plasma-activated media on 3D multicellular tumor spheroids. Sci Rep 6: 21421, 2016. PMID: 26898904. DOI: 10.1038/srep21421

33 Kim TH, Kim JS, Kim ZH, Huang RB, Chae YL and Wang RS: KHZ-CP (crude polysaccharide extract obtained from the fusion of Ganoderma lucidum and Polyporus umbellatus mycelia) induces apoptosis by increasing intracellular calcium levels and activating p38 and NADPH oxidase-dependent generation of reactive oxygen species in SNU-1 cells. BMC Complement Altern Med 14: 236, 2014. PMID: 25012725. DOI: 10.1186/1472-6882-14-236

34 Kim SL, Choi HS, Kim JH, Jeong DK, Kim KS and Lee DS: Dihydrotanshinone-induced nox 5 activation inhibits breast cancer stem cell through the ROS/STAT3 signaling pathway. Oxid Med Cell Longev 2019: 9296439, 2019. PMID: 31019654. DOI: $10.1155 / 2019 / 9296439$ 
35 Kim KC, Piao MJ, Madduma Hewage SR, Han X, Kang KA, Jo JO, Mok YS, Shin JH, Park Y, Yoo SJ and Hyun JW: Nonthermal dielectric-barrier discharge plasma damages human keratinocytes by inducing oxidative stress. Int J Mol Med 37(1): 29-38, 2016. PMID: 26573561. DOI: 10.3892/ijmm.2015.2405

36 Lin A, Truong B, Patel S, Kaushik N, Choi EH, Fridman G, Fridman A and Miller V: Nanosecond-pulsed DBD plasmagenerated reactive oxygen species trigger immunogenic cell death in A549 lung carcinoma cells through intracellular oxidative stress. Int J Mol Sci 18(5), 2017. PMID: 28467380 DOI: $10.3390 /$ ijms18050966

37 Smolkova B, Lunova M, Lynnyk A, Uzhytchak M, Churpita O, Jirsa M, Kubinova S, Lunov O and Dejneka A: Non-thermal plasma, as a new physicochemical source, to induce redox imbalance and subsequent cell death in liver cancer cell lines. Cell Physiol Biochem 52(1): 119-140, 2019. PMID: 30790509. DOI: $10.33594 / 000000009$

38 Luo HR, Hattori H, Hossain MA, Hester L, Huang Y, Lee-Kwon W, Donowitz M, Nagata E and Snyder SH: AKT as a mediator of cell death. Proc Natl Acad Sci USA 100(20): 11712-11717, 2003. PMID: 14504398. DOI: 10.1073/pnas.1634990100

39 Subramaniam A, Shanmugam MK, Perumal E, Li F, Nachiyappan A, Dai X, Swamy SN, Ahn KS, Kumar AP, Tan BK, Hui KM and Sethi G: Potential role of signal transducer and activator of transcription (STAT)3 signaling pathway in inflammation, survival, proliferation and invasion of hepatocellular carcinoma. Biochim Biophys Acta 1835(1): 4660, 2013. PMID: 23103770 DOI: 10.1016/j.bbcan.2012.10.002

40 Liu C, Sun HN, Luo YH, Piao XJ, Wu DD, Meng LQ, Wang Y, Zhang Y, Wang JR, Wang H, Xu WT, Li JQ, Liu Y, Wu YQ, Han YH, Shen GN, Jin MH, Zang YQ, Li JC, Fang NZ, Cui YD and Jin $\mathrm{CH}$ : Cryptotanshinone induces ROS-mediated apoptosis in human gastric cancer cells. Oncotarget 8(70): 115398-115412, 2017. PMID: 29383168. DOI: 10.18632/oncotarget.23267
41 Okamoto K, Kondo-Okamoto N and Ohsumi Y: Mitochondriaanchored receptor ATG32 mediates degradation of mitochondria via selective autophagy. Dev Cell 17(1): 87-97, 2009. PMID: 19619494. DOI: 10.1016/j.devcel.2009.06.013

42 Maycotte P, Jones KL, Goodall ML, Thorburn J and Thorburn A: Autophagy supports breast cancer stem cell maintenance by regulating IL6 secretion. Mol Cancer Res 13(4): 651-658, 2015. PMID: 25573951. DOI: 10.1158/1541-7786.MCR-14-0487

43 Tao Z, Li T, Ma H, Yang Y, Zhang C, Hai L, Liu P, Yuan F, Li J, Yi L, Tong L, Wang Y, Xie Y, Ming H, Yu S and Yang X: Autophagy suppresses self-renewal ability and tumorigenicity of glioma-initiating cells and promotes NOTCH1 degradation. Cell Death Dis 9(11): 1063, 2018. PMID: 30337536. DOI: 10.1038/s41419-018-0957-3

44 You L, Shou J, Deng D, Jiang L, Jing Z, Yao J, Li H, Xie J, Wang Z, Pan Q, Pan H, Huang W and Han W: Crizotinib induces autophagy through inhibition of the STAT3 pathway in multiple lung cancer cell lines. Oncotarget 6(37): 40268-40282, 2015. PMID: 26384345. DOI: 10.18632/oncotarget.5592
Received October 4, 2019

Revised October 22, 2019 Accepted October 29, 2019 